\title{
Exploring the Unknown: The Autonomy of Saudi EFL Learners
}

\author{
Fakieh Alrabai $^{1}$ \\ ${ }^{1}$ King Khalid University, Saudi Arabia \\ Correspondence: Fakieh Alrabai, King Khalid University, Saudi Arabia. E-mail: falrabei@kku.edu.sa
}

Received: March 6, 2017 Accepted: April 25, 2017 Online Published: April 27, 2017

doi: 10.5539/elt.v10n5p222 URL: http://doi.org/10.5539/elt.v10n5p222

\begin{abstract}
This study addresses a new area of research in Saudi Arabia. Using a sample of 630 Saudi students, it investigates learners' level of autonomy and its relationship to academic achievement in English as a foreign language (EFL). Learners' level of autonomy was measured by a survey, whereas their achievement was evaluated using standardized achievement tests. The data were analyzed using descriptive analyses and a t-test. The findings revealed that learners were non-autonomous, with a mean autonomy score of 2.35 out of 5; and also low language achievers $(M=66$ out of 100). Gender had a significant effect on autonomy and achievement. These findings emphasize the vast lack of awareness of the vital role of learner autonomy in the Saudi EFL setting. The study suggests that Saudi learners and teachers alike require increased awareness of the importance of the concept of autonomy and that practical means to promote Saudi EFL learner autonomy should be sought and practiced.
\end{abstract}

Keywords: autonomy; achievement; EFL; independent learning; Saudi Arabia education

\section{Background}

Despite the increasing interest in learner autonomy in language education worldwide over the past several decades, this crucial concept has not received attention in the Saudi EFL context. To the best of the researcher's knowledge, no study to date has ever investigated the issue of EFL learner autonomy in Saudi Arabia. Lack of any significant research on language autonomy in the Saudi context has been therefore one of the key driving forces behind the current study.

\section{Review of Related Literature}

This section presents a review of the literature related to the definition of autonomy, the importance of autonomy, the levels of learner autonomy, the characteristics of autonomous learners, and the relationship between learner autonomy and EFL achievement.

\subsection{What Is Learner Autonomy?}

Learner autonomy has been a key theme in the field of foreign language (FL) learning for several decades. Nevertheless, because of the multidimensionality and complexity of autonomy, there is continued debate in the literature concerning the definition of the concept. Ikonen (2013) indicates that the definition of autonomy varies in the literature despite the substantially growing interest in this concept in education in general and in the field of language learning in particular. Sella (2014) emphasizes that there is no single conclusive definition of autonomy, although there is a general agreement among researchers on a definition that was first introduced by Holec (1981, p. 3), who defined autonomy as '...the ability to take charge of one's own learning.' According to Benson (2009), Ikonen (2013), and Sella (2014), this definition has been the most frequently cited definition of learner autonomy in the literature. According to this definition, the learner must be actively engaged in learning and be responsible for all of the decisions related to it: goals, content, and methods, in addition to the monitoring and evaluation of learning. Benson (2009) adds that 'ability' and 'take charge of' in this definition were subsequently replaced by 'capacity' and 'take responsibility for;' respectively.

Little (1991, p. 4) also defines autonomy as 'a capacity for detachment, critical reflection, decision making, and independent acquisition.' This definition further emphasizes the learner's responsibility to make conscious choices and to think critically about his/her learning (Sella, 2014).

\subsection{Why Is Learner Autonomy Important?}

Autonomy is a highly important concept that is not only a fundamental feature of all learning but also a concept 
central to the field of FL learning in particular. It has significant implications for both individual learners and educators alike. With respect to the individual learner, Little (2003) argues that learner autonomy is critical for at least three reasons. The first is that, if students actively participate in their learning, then they will most likely be more efficient and more effective. According to Ikonen (2013), this argument is often justified because being able to take responsibility and control over one's learning implies the existence of such features of efficient learning as intrinsic motivation, metacognitive skills, awareness of the subject, and awareness that learning is a process. The second reason, according to Little (2003), is that, when students are actively engaged in learning, they become motivated to learn, which enables them to overcome the problems associated with lack of motivation. The third reason is more closely related to language education because of the nature of languages themselves; learning a language requires being able to communicate effectively, and effective communication involves many complex skills that can be developed only by actively using the language in natural communication.

Benson (2011) states that, although there is still insufficient empirical evidence as to the efficiency of autonomous learning, it stands to reason that a person who knows how to learn learns efficiently. Further, learner autonomy promotes life-long learning (Ikonen, 2013; Kohonen, 1992), which is necessary to achieve long-term learning goals and, in turn, better learning outcomes. Moreover, Pennycook (1997) highlights the fact that learner autonomy is highly empowering because autonomous learners gain their own voice and become the authors of their own story. Furthermore, Sella (2014) states that autonomy encourages learners to be more willing to use the language, with little or no fear of failing, and are thus more likely to become successful users of the language.

Regarding educators, Yang (1999) clarifies that the increasing necessity to teach students how to become independent and autonomous learners has brought new perspectives to the teaching profession and has changed traditional ideas about language teachers' roles, such that the new roles of being helpers, facilitators, advisors, and guides have been adopted and incorporated into teaching practices.

\subsection{Levels of Learner Autonomy}

In addition to being perceived as a continuum of an inherent capacity, autonomy has also been described in terms of stages of development. Littlewood (1996) elucidates that autonomy consists of three domains that describe the learner's level of autonomy and the types of choices that he/she is able to make at a particular level: the communicative level, the learning level, and the personal level. At the communicative level, the learner is able to make choices about language use and appropriate strategies in communicating meanings in different situations and specific tasks. At the learning level, he/she can use appropriate learning strategies independently. At the personal level, the student is able to make choices about his/her language learning in a broader context (e.g., creating personal learning contexts).

Nunan (1996) proposed a five-level autonomy model that involves awareness, involvement, intervention, creation and transcendence. In light of this model, learners are made aware of the pedagogical goals and content of the materials at the awareness level; while, at the involvement and the intervention level, they identify their own preferred learning styles and strategies and their implications of pedagogical tasks. At the transcendence level, learners make links between the content of classroom learning and the world beyond.

Scharle and Szabo (2000) proposed a three-phase model involving raising awareness, changing attitudes, and transferring roles. Similarly, Macaro (2005) suggested a three-stage model that includes autonomy of language competence, language learning competence, and autonomy of choice and action, as shown in Table 1 below.

Table 1. Levels of autonomy

\begin{tabular}{llll}
\hline \begin{tabular}{l} 
Littlewood's Model \\
\multicolumn{1}{c}{$(1996)$}
\end{tabular} & $\begin{array}{l}\text { Nunan's Model } \\
(1996)\end{array}$ & $\begin{array}{c}\text { Scharle \& Szabo's } \\
(2000)\end{array}$ & \multicolumn{1}{c}{$\begin{array}{c}\text { Macaro's Model } \\
(2005)\end{array}$} \\
\hline - Autonomy as a & - Awareness. & -Raising Awareness. & - Autonomy of language \\
communicator. & - Involvement. & -Changing attitudes. & $\begin{array}{l}\text { competence. } \\
\text { - Autonomy as a learner. }\end{array}$ \\
- Autonomy as a person. & - Intervention. & -Transferring roles. & $\begin{array}{l}\text { - Autonomy of language } \\
\text { learning competence. }\end{array}$ \\
& - Creation. & & - Autonomy of choice \\
& - Transcendence. & & and action. \\
\hline
\end{tabular}




\subsection{Characteristics of Autonomous Language Learners}

There have been many attempts to compile lists of the characteristics of autonomous language learners. A seven-point list is compiled by Wenden (1998), who maintains that the autonomous learner is a learner who has insight into his/her learning style and strategies, takes an active approach and is willing to take risks, is a good guesser, pays attention to both form and content when using the language, develops his/her own reference system for the target language and is willing to reject hypotheses that do not apply.

Breen and Mann (1997) propose a similar list that is composed of eight qualities that characterize the autonomous learner. According to them, the autonomous learner is a learner who demonstrates a learner's stance, which is his/her relationship with the content that he/she has to learn with the resources available, has a desire to learn that specific language, has a strong sense of self (e.g., high self-confidence), has metacognitive capacity (i.e., can step back from the task at hand and reflect on it and its usefulness), is able to manage change (i.e., is alert to change and is able to change in an adaptable, resourceful, and opportunistic manner because of his/her metacognitive capacity), demonstrates independence from the educational framework of the classroom, is strategically engaged with learning (i.e., makes use of the environment in a strategic manner), and has the ability to negotiate with the other actors involved in his/her learning process.

Other researchers, such as Little (1991), Sella (2014), and Ushioda (1996), have proposed that autonomous language learners in formal educational contexts are typically able to take charge of their own learning and develop a capacity for detachment, critical reflection, decision making and independence; they can manage the affective dimension of their learning experience to their advantage and become more autonomous in language learning in direct proportion to the degree to which they become more autonomous in language use, and vice versa.

\subsection{Autonomy and L2 Achievement}

Learner autonomy has been identified as a complicated capacity that potentially has a significant effect on personal growth and achievement. Several researchers (e.g., Corno \& Mandinach, 1983; Dafei, 2007; Risemberg \& Zimmerman, 1992; Zhang \& Li, 2004) have hypothesized that greater autonomy may ultimately lead to greater proficiency in language use and have further concluded that autonomous learners are those with high language proficiency. Similarly, Risenberg and Zimmerman (1992) note that high-achieving students with a high degree of autonomy would achieve high scores whereas those with low degrees of autonomy would be likely to achieve low scores. In addition, Zhang and Li (2004) conclude that learner autonomy is closely related to the language level.

However, these theoretical assumptions have not been empirically validated to date. Dafei (2007) emphasizes that there is a need for empirical research that examines the relationship between the development of autonomy and language proficiency and demonstrates the practices required to foster the autonomy that leads to better language learning outcomes. Such research also needs to describe the ways in which proficiency develops as a result of the distinctive qualities of practices that are designed to promote autonomy. Further, Benson (2011) indicates that research must establish criteria of proficiency and assessment tools that are relevant to autonomous learning to document the ways in which the development of autonomy and proficiency interact (p. 191).

\section{Method}

This section describes the goals and research questions of the study, the participants, instruments, and data collection, in addition to the data analysis.

\subsection{Goals and Research Questions}

Because learner autonomy is designed to allow students to be heard, a major objective of this study is to explore Saudi learners' perceptions of a number of aspects of independent learning to evaluate the degree of autonomy that they exhibit while learning English as a foreign language. Therefore, this study is designed to answer the following questions:

1) To what degree are Saudi EFL learners autonomous?

2) What is the degree of EFL achievement among Saudi EFL learners?

3) What is the relationship between the levels of autonomy and EFL achievement of Saudi EFL learners?

4) Are there any gender differences in autonomy and achievement among Saudi learners?

\subsection{Participants (Subjects) Characteristics}

The participants were 630 volunteer EFL learners who were recruited over two semesters of the Saudi academic 
year. The participating students were Saudi nationals and native speakers of Arabic. The selection of participants (including their gender) was completely random, occurred in both rural and urban areas of the country, and was designed to cover the different sectors of public education in Saudi Arabia as widely as possible. The study recruited 386 English-major and 244 non-English-major students from four different geographic areas of the country. Additional information about the students who participated in this study is presented in Table 2.

Table 2. Social demographic information for the participating learners $(N=630)$

\begin{tabular}{|c|c|c|c|c|}
\hline \multirow{3}{*}{ Demographic variable } & \multicolumn{4}{|c|}{ Condition } \\
\hline & \multicolumn{2}{|c|}{ Male $(N=303,48.10 \%)$} & \multicolumn{2}{|c|}{ Female $(N=327,51.90 \%)$} \\
\hline & FQ & $\%$ & FQ & $\%$ \\
\hline \multicolumn{5}{|l|}{ Age } \\
\hline $15-18$ years old & 28 & 9.24 & 34 & 10.40 \\
\hline 18-22 years old & 118 & 38.94 & 123 & 37.62 \\
\hline $22-25$ years old & 139 & 45.88 & 156 & 47.70 \\
\hline$>25$ years old & 18 & 5.94 & 14 & 4.28 \\
\hline \multicolumn{5}{|l|}{ School level } \\
\hline Intermediate school & 29 & 9.57 & 33 & 10.09 \\
\hline High school & 124 & 40.92 & 118 & 36.09 \\
\hline University & 150 & 49.51 & 176 & 53.82 \\
\hline \multicolumn{5}{|l|}{ Region of origin } \\
\hline Central region & 63 & 20.79 & 76 & 23.24 \\
\hline Eastern region & 32 & 10.56 & 28 & 8.56 \\
\hline Western region & 98 & 32.34 & 106 & 32.42 \\
\hline Southern region & 110 & 36.31 & 117 & 35.78 \\
\hline
\end{tabular}

Note: $\mathrm{FQ}=$ frequency, $\%=$ percentage.

\subsection{Measurements}

This study used a questionnaire and a standardized test. To gather data about the informants' autonomous learning behavior, a five-point Likert scale with options that ranged from 'strongly disagree' to 'strongly agree' was used. This measurement was adapted from Zhang and Li (2004), Dafei (2007), Macaskilla and Taylor (2010), and Joshi (2011), with slight modifications. The English version of the 28 -item autonomy questionnaire is presented in Appendix A. A verified Arabic translation of the questionnaire was obtained, and the tool was administered in Arabic, the respondents' native language, to eliminate the risk that some respondents' limited English competency would affect their ability to properly respond to the questionnaire.

The second instrument used was a standardized achievement test that was designed to measure learners' attainment of what they have learned during English language course in four skills: listening, reading, grammar, and writing. The items on achievement tests were drawn from a question bank consisting of more than 200 questions that were developed, examined and evaluated by experts in the fields of linguistics, education, and language evaluation and assessment.

\subsection{Data collection and Procedures}

\subsubsection{Piloting}

The questionnaire survey was piloted with 73 EFL students prior to the main study. This instrument demonstrated high content validity and reliability $(\alpha=0.82)$.

When designing the questions of the achievement tests, a test plan was formulated to accurately represent the content, objectives, and depth of each course to ensure the validity of the achievement tests. Different samples of questions were administered to two groups of learners during the pilot test, and the results were highly repeatable, confirming the accuracy of the students' scores and therefore the reliability of achievement tests. 


\subsubsection{The Main Study}

To satisfy research ethics requirements, the institutions' approval and the participants' own consent were sought and granted before the study commenced. The study was conducted over two semesters of the Saudi academic year (October 2015-May 2016). On the day that the autonomy questionnaire was administered, comprehensive information about the study and detailed instructions for completing the questionnaire were presented to the participants. Before completing the questionnaire, each respondent was asked to fill out a demographic information sheet that included gender, age, and learning experience. The researcher himself directly administered the questionnaire to male students in the absence of school teachers/administrators, whose presence might affect students' responses. The learners were assured that their responses would remain entirely confidential and anonymous. The students required 30-40 minutes to complete the entire questionnaire. For cultural considerations, the researcher did not have access to female institutions and was thus unable to recruit female participants himself. A very experienced female researcher volunteered to administer the questionnaire to female participants. She maintained all of the research ethical considerations and precisely followed the same procedures that were used to recruit male participants.

Achievement tests were administered three times. The first two tests were mid-term progress tests, with a maximum possible score of 25 points. The third test was the final exam, with a maximum possible score of 50 points. Thus, the maximum possible score for all three tests was 100 points. The final exam score was divided by 2 to make it comparable in value to the progress tests. All tests were written and completed in groups during a normal class session. Multiple-choice tests were used to measure learners' achievement in grammar, reading and listening. Written tests were in short-answer or essay format. The listening, reading and grammar tests were marked following objective criteria, whereas the writing tests were scored using a holistic approach. Mean scores for English achievement (overall competence) were obtained by summing the results in the four skill tests.

\subsection{Data Analysis}

The data collected were subjected to preliminary statistical analyses, such as Cronbach's alpha for internal consistency, item analysis, explanatory factor analysis (EFA), and normality tests. Two factors emerged as a result of the EFA that was conducted on the autonomy questionnaire to reveal the constructs underlying the dimensions in this scale. The two factors were strongly correlated $(r=0.83)$. They alone explained over $71 \%$ of the variability in the respondents' scores. The first factor explained $51.03 \%$ of the variance and had loadings from items 8-28 (see Appendix A). This factor was labeled 'learners' capacity for independent learning.' The scale had an alpha value $=0.78$, and all items had correlations greater than 0.40 . The second factor $(19.97 \%$ of the variance) comprised variables 1-7 of the questionnaire items. This factor was labeled 'self-efforts in learning English' $(\alpha=0.76, r>0.30)$. In addition to the EFL results, all final versions of the instruments suggested that the data were reliable and that all constructs were distributed normally.

Descriptive statistics were computed on the data of the main study to identify the levels of autonomy and achievement of the participating students. A t-test was also performed to detect the role of the learners' gender in their autonomy and achievement.

\section{Results and Discussion}

The answers to the four research questions are presented and discussed below as follows:

\section{1). To what degree are Saudi EFL learners autonomous?}

The mean score was used to measure learners' autonomous behavior. The percentage of this mean was then computed to make it comparable to the percentage of learners' achievement. The study adopted the following operational categorization hypothesized by Elizondo and Garita (2013) for the degree of learner autonomy: students with autonomy mean scores above 4 out of $5(80 \%)$ were categorized as highly autonomous; those with mean scores ranging from 3 to 4 out of 5 (60 to 80\%) were considered somewhat autonomous, whereas learners with mean scores below 3 out of $5(<60 \%)$ were considered non-autonomous.

The mean score for learner autonomy among the students recruited in this study was 2.35 out of $5(47.08 \%)$, $\mathrm{SD}=.51$. This finding reveals that Saudis are considered non-autonomous EFL learners. This low score is very disappointing, but given the nature of the learning environment in which those students are typically involved, it should not be surprising. It comes in line with what Al-Saadi (2011) claims that the schooling system in the Saudi setting has failed to create curious and autonomous learners who are willing and see the need to take control of their own learning, or at least some aspects of their learning such as self-assessment and reflection.

The reasons for the relative lack of learner autonomy in the Saudi EFL context are diverse and multidimensional. The most important of these reasons is the students' over-reliance on teachers and the spoon-feeding habits that 
are prevalent in this context. Tamer (2013) clarifies that, in the Saudi Arabian context, traditional rote learning in teacher-controlled classrooms still continues and that the roles of teachers and students remain essentially the same, in that teachers lecture and students listen. He added that this type of teacher-student relationship starts early in elementary school and continues through secondary school and high school, leading to learners at the university level who mostly bear the characteristics of dependent learners and who are typically accustomed to following rather than leading.

Another reason for undermining learner autonomy in FL education in Saudi Arabia is that this concept has remained unnoticed in decision making. The FL curriculum is a simple example of the manner in which learner autonomy is overlooked. In Saudi Arabia, course design is regulated according to a binding curriculum that defines the general outlines of each course and thus makes the range of choices necessarily limited. A third example for how learner autonomy is overlooked in the Saudi setting is the lack of teacher training on up-to-date teaching methods that encourage them to involve learners in self-directed learning. The majority of FL teachers there follow traditional methods of teaching (e.g., the grammar translation method) to educate language learners.

The lack of learner training on certain skills that contribute in the development of learner autonomy such as self-management, self-monitoring and self-assessment is another important factor behind ignoring learner autonomy in the Saudi EFL setting.

As for the two constructs of learner autonomy that emerged from factor analysis, the respondents had low mean scores on the two factors, $\mathrm{M}=2.40$ for 'learners' capacity for independent learning' and $\mathrm{M}=2.21$ for 'self-efforts in learning English,'emphasizing that learners were non-autonomous on both factors.

In light of the data in Appendix A, which present the mean scores of each item of the questionnaire based on the participants' responses, we can categorize Saudi EFL learners' autonomy into four distinct levels. The participants reported a low level of autonomy on $53.57 \%$ of the questionnaire (15 items), followed by very low levels on 8 items ( $28.57 \%$ of the survey items) and a moderate level of autonomy on only 5 items $(17.86 \%$ of the questionnaire items), and they reported a complete lack of high autonomy ( 0 items, $0 \%$ of the questionnaire items).

The participants reported low levels of FL autonomy on the majority of the survey items of this study (items \# 10, $26,1,25,17,12,18,21,9,14,15,19,11,6$, and 13; in descending order of the mean). The respondents also ranked very low on items \# 4, 3, 7, 20,23, 27, 5, and 28. The low and very low levels of autonomy that the participating learners reported on these items is a clear indication of the lack of EFL autonomy of learners because these items represent very important aspects of learner autonomy, such as making decisions about learning (e.g., items \# 11 and 28), taking control over learning (e.g., items \# 25, 17, 15, and 23), exhibiting a willingness to take risks and accept challenges (e.g., items \# 26, 12, 14, and 13), enhancing metacognitive skills and self-assessment (item \# 7), recognizing one's own strengths and weaknesses (item \# 10), planning and implementing suitable learning strategies (e.g., items \# 6, 4, 27 and 5), and demonstrating a high sense of self (e.g., items \# 21 and 20). The item with the lowest mean score in the survey was item \# $28(\mathrm{M}=1.05)$. The learners' responses on this item showed that they are very rarely involved in choosing the material that they study, which reflects a broad absence of learner autonomy in this regard.

The participating learners reported moderate levels of autonomy on only five items. The item in the survey with the highest mean was item \# 2: 'I attend my English language classes regularly' $(\mathrm{M}=3.37)$. Although students' responses on this item may be considered an indication of some degree of autonomy, its actual meaning is very different. The learners' score on this item reflects one of the policies in Saudi academic institutions, in which a regular student must attend a minimum of $75 \%$ of the classes and lab sessions for each course during the semester. In light of the Undergraduate Study and Examinations Regulations released by the Ministry of Higher Education in Saudi Arabia in 2012, a student may be dropped from a course and be denied entrance to the final examination if his/her number of unexcused absences exceeds the limit determined by the academic institution (typically $25 \%$ of the total number of classes per semester). Therefore, students' scores on this item are misleading because they are simply a response to these obligatory regulations rather than being a representation of true autonomy.

The second statement that appeared to represent a moderate level of autonomy was item \# 16: 'When I become involved in difficult tasks in English language classes, I try to stick with them' $(\mathrm{M}=3.22)$. The students' responses to this statement could be considered a sign of a moderate degree of autonomy, but, in fact, they contradict their responses to other statements in the survey, such as item \# 14: 'I enjoy being set at a challenge in English language classes,' which received a low mean score $(\mathrm{M}=2.25)$. This contradiction in the students' responses demonstrates their uncertainty about, and lack of awareness of, their autonomous behavior. This lack 
of awareness was further demonstrated in their responses to item \# 4: 'Whether students should design the teaching plan together with teachers or not, my opinion is...'; most students selected the 'neutral' option. In the responses to item \# 6: 'When I meet a word I do not know, I mainly...', the majority of respondents emphasized that they typically 'guess the meaning' of unfamiliar words. This is evidence that the students fail to use proper learning strategies and are unaware of an important aspect of their autonomy. This lack of awareness was also well represented in the participants' responses to item \# 8: 'I think I have the ability to learn English well,' to which most indicated that they 'sometimes' believe they have the ability to learn English.

The data in Appendix A reveal that the participating learners did not report high levels of autonomy on any of the questionnaire items, thereby confirming that none of the Saudi EFL learners recruited in the present study demonstrated high autonomy. Based on all of the findings reported in Appendix A, it is clear that the levels of autonomy that Saudi EFL learners' in this study demonstrated could not be ranked on any of the models provided in Table 1 because, in most cases, they lack any of the features provided in these models.

\section{2). What is the degree of EFL achievement of Saudi EFL learners?}

The mean score of learners' achievement was 66.02 out of 100. In light of the classification provided in earlier studies for learner achievement levels (e.g., Alrabai \& Moskovsky, 2016), the learners in this study are considered low EFL achievers. The low achievement of Saudi EFL learners could be attributed to a variety of factors. Some of these are learner-related demographic variables, such as gender, age, motivation, attitudes, aptitude, anxiety, autonomy, and learning strategies and style. Others are sociocultural factors (e.g. the Arabic mother tongue; religion, culture, and society); instructional variables, such as teacher behavior and teaching styles, the curriculum and teaching methods; in addition to educational system faults, such as overcrowded classes, and a lack of teacher training and technology. The reader may refer to Alrabai's (2016) study, which presents a detailed discussion of these factors.

\section{3). What is the relationship between the autonomy levels and achievement of Saudi EFL learners?}

The findings reported in Table 3 show that the correlation coefficient $\left(r=0.30^{* *}\right)$ is relatively close to 1 and that the significance level $(p<0.01)$ is very small; this finding indicates that the correlation between learner autonomy and English achievement on the part of the Saudi EFL learners involved in this study was significantly positive and linear, which suggests that their English language achievement increases with their autonomy, and vice versa. This suggestion is consistent with the work by Dafei (2007), who found that Chinese students' English proficiency is significantly and positively related to their autonomy. It also confirms what is established by Zhang and $\mathrm{Li}$ (2004) and Risenberg and Zimmerman (1992), namely, that learner autonomy is closely related to language achievement levels, such that a student with a high degree of learner autonomy will achieve high academic scores whereas those with a low degree of learner autonomy are likely to achieve low scores. This was precisely the case with the participants in this study, who exhibited low levels of both autonomy and academic achievement, which strongly suggests that their low autonomy is a factor that significantly contributes to their low competence in English.

Table 3. Pearson correlation coefficient $(r)$ between learners' autonomy and their EFL achievement

\begin{tabular}{ll}
\hline Variable & Learner EFL Achievement \\
\hline Learner autonomy & $0.30^{* *}$ \\
\hline
\end{tabular}

Note. ${ }^{* *}$, Correlation is significant at $\mathrm{p}<0.01$.

\section{4). Does gender influence Saudi EFL learners' autonomy and achievement?}

An independent-samples t-test was performed to explore the possibility that there were gender-based differences in the participants' autonomy and achievement. The data in Table 4 show that there was a significant gender difference among learners with respect to their autonomy: females $(\mathrm{M}=2.44, \mathrm{SD}=0.53)$; males $(\mathrm{M}=2.26, \mathrm{SD}$ $=0.49) ; \mathrm{t}_{628}=4.41, p=0.000$. There was also a significant gender difference in the participants' achievement: females $(\mathrm{M}=3.38, \mathrm{SD}=0.63)$; males $(\mathrm{M}=3.22, \mathrm{SD}=0.81) ; \mathrm{t}_{628}=2.68, p=0.01$. These findings are consistent with earlier studies (e.g., Abidin, Mohammadi, and Alzwari, 2012; Shoaib and Dörnyei, 2005) that concluded that females typically show more interest and positive behaviors and performance compared to their male counterparts, suggesting that gender is an important variable in second language learning. Despite the significant differences in autonomy and achievement among the participants in this study, all in favor of female learners, both genders remained, however, non-autonomous and low achievers in the English language. 
Table 4. Independent samples t-test of students' autonomy and achievement by gender $(N=630)$

\begin{tabular}{lllllllllllr}
\hline Gender & $N$ & $M$ & $S D$ & $t$ & $d f$ & Sig & $M$ & $S D$ & $t$ & $d f$ & Sig \\
\hline Females & 327 & 2.44 & 0.53 & 4.41 & 628 & 0.000 & 3.38 & 0.63 & 2.68 & 628 & 0.01 \\
Males & 303 & 2.26 & 0.49 & & & & 3.22 & 0.81 & & & \\
\hline
\end{tabular}

Note: $N=$ Total number of participants, $M=$ Mean, $S D=$ Standard deviation, $t=$ t-value, $d f=$ degree of freedom, Sig $=$ p-value.

\section{Conclusions}

This study examined the relationship between Saudi EFL learners' autonomy and their EFL achievement. The participants demonstrated low levels of autonomy in learning English and low levels of EFL achievement. The results also showed that learners' autonomy and achievement were significantly and positively correlated. These findings can be attributed to a variety of factors that play a role in low autonomy and achievement. A significant contribution of this study is that it is the first in the Saudi EFL context to investigate the levels of autonomy of Saudi EFL learners and to assess the relationship between this variable and Saudi learners' achievement in English as a foreign language.

The need to incorporate learner autonomy into EFL education in Saudi Arabia is well justified. Individual researchers and educators must set this practical movement into motion, after which changes must be implemented in larger educational structures so that autonomy becomes a part of everyday teaching practices in the country. The first recommendation of this study is that learners and teachers alike must be made aware of the crucial role that autonomy plays in the learning process. A preliminary step in enhancing learners' awareness of autonomy is learner training. Training learners on certain skills such as self-management, self-monitoring and self-assessment would be an important factor in the development of learner autonomy. Benson (2011) reports that training learners who were used to teacher-centered education on such skills would make them psychologically prepared for more learner-centered learning. Kocak (2003) emphasizes that it would be effective to provide learner training together with the program and to make it an integral part of the course to help learners become autonomous. For this training to be successful, Little (1995) states that it is difficult for learners in formal education contexts to immediately accept responsibility for their learning, and he adds that it is the teachers who will help them do so gradually by equipping them with sufficient materials and with chances to practice them. This emphasizes the need for promoting teachers' awareness of autonomy. Enhancing awareness of learner autonomy on the part of the teachers could be achieved by investigating their perceptions of autonomy and the challenges that they face in involving learners in independent learning. These teachers could then receive training on methods by which to involve students in autonomous learning, using practical means designed to promote autonomy like utilizing technology means such as the Internet and Smartphones. Bawazeer (2015) emphasized that students should be allowed and encouraged to use these tools since they work against memory-based teaching system and hence enable autonomy and control of learning on the part of learners.

After rising learners' awareness of autonomy, their readiness for self-directed learning should be tested and evaluated. Investigating Saudi EFL learners' readiness for independent learning and finding methods to promote their autonomy in learning English are issues that future research should investigate.

One limitation of this study is that it did not evaluate the possibility that the low levels of learner autonomy were the reason for the learners' low EFL achievement. Doing so would require a longitudinal investigation that allows stringent inferences of causality by examining the relationship between the two variables (i.e., learner autonomy and EFL achievement) via an experimental intervention. Because this was beyond the scope of this study, future studies in the field should examine such a relationship.

Another limitation of the current research is that the only approach utilized was a quantitative approach via a questionnaire survey. This approach not only allows a large volume of data to be gathered and analyzed relatively quickly but also enabled us to replicate previous studies and thus compare the results obtained about learner autonomy in other EFL contexts. However, the lack of triangulation of instruments that exclusively relied on a self-reporting method, which has its own limitations, may not necessarily provide the full image of the learner's autonomous behavior. Future research is thus advised to employ a mixed-methodology approach that can be utilized to gather both qualitative and quantitative data to examine learner autonomy in greater depth. 


\section{References}

Abidin, Z. M., Mohammadi, M. P., \& Alzwari, H. (2012). "EFL Students' Attitudes towards Learning English Language: The Case of Libyan Secondary School Students.” Asian Social Science, 8(2), 119-134.

Al-Saadi, H. (2011). From Spoon Feeding to Self-Feeding: Helping Learners Take Control of Their Own Learning. Arab World English Journal, 2(3), 95-114.

Alrabai, F. (2016). Factors Underlying Low Achievement of Saudi EFL Learners. International Journal of English Linguistics, 6(3), 21-37. https://doi.org/10.5539/ijel.v6n3p21

Alrabai, F., \& Moskovsky, C. (2016). The Relationship between Learners' Affective Variables and Second Language Achievement. Arab World English Journal, 7(2), 77-103.

Bawazeer, K. (2015). A system for Teaching English in Saudi Arabia. In A. Hamdan (Ed.), Teaching and Learning in Saudi Arabia: Perspectives from Higher Education. Rotterdam, The Netherlands: Sense Publishers. https://doi.org/10.1007/978-94-6300-205-9_2

Benson, P. (2009). Making Sense of Autonomy in Language Learning. In In R. Pemberton, S. Toogood, \& A. Barfield (Eds.), Maintaining Control: Autonomy and Language Learning (pp. 13-26). Hong Kong: Hong Kong University Press. https://doi.org/10.5790/hongkong/9789622099234.003.0002

Benson, P. (2011). Teaching and Researching Autonomy. 2nd ed. London, UK: Taylor \& Francis.

Breen, M. P., \& Mann, S. J. (1997). Shooting Arrows at the Sun: Perspectives on a Pedagogy for Autonomy. In P. Benson, \& P. Voller (Eds.), Autonomy and Independence in Language Learning (pp. 132-149). London and New York: Longman.

Corno, L., \& Mandinach, E. B. (1983). The Role of Cognitive Engagement in Classroom Learning and Motivation. Educational Psychologist, 18(2), 88-108. https://doi.org/10.1080/00461528309529266

Dafei, D. (2007). An Exploration of the Relationship between Learner Autonomy and English Proficiency. Asian EFL Journal, 24(4), 24-34.

Elizondo, L. B., \&Garita, C. O. (2013). A Closer Look into Learner Autonomy in the EFL Classroom. Revista de Lenguas Modernas, 19, 325-343.

Holec, H. (1981). Autonomy and Foreign Language Learning. Oxford, UK: Pergamon.

Ikonen, A. (2013). Promotion of Learner Autonomy in the EFL Classroom: The Students' view. Unpublished Master's thesis, University of Jyväskylä.

Joshi, K. R. (2011). Learner Perceptions and Teacher Beliefs about Learner Autonomy in Language Learning. Journal of NELTA, 16(1), 13-9.

Kocak, A. (2003). A Study on Learners' Readiness for Autonomous Learning of English as a Foreign Language. Master's thesis, Middle East Technical University.

Kohonen, V. (1992). Experiential Language Learning: Second Language Learning as Cooperative Learner Education. In D. Nunan (Ed.), Collaborative Language Learning and Teaching (pp. 14-39). Cambridge, UK: Cambridge University Press.

Little, D. (1991). Learner Autonomy 1: Definitions, Issues and Problems. Dublin, Ireland: Authentik Language Learning Resources, Ltd.

Little, D. (1995). Learning as Dialogue: The Dependence of Learner Autonomy on Teacher Autonomy. System, 23(2), 175-181. https://doi.org/10.1016/0346-251X(95)00006-6

Little, D. (2003). Learner Autonomy and Second/foreign Language Learning. Guide to Good Practice. https://www.llas.ac.uk/resources/gpg/1409

Littlewood, W. (1996). Autonomy': An Anatomy and a Framework. System, 24(4), 427-435. https://doi.org/10.1016/S0346-251X(96)00039-5

Macaro, E. (2005). Teaching and Learning a Second Language: A Guide to Recent Research and its Applications London, UK: Bloomsbury Academic.

Macaskill, A., \& Taylor, E. (2010). The Development of a Brief Measure of Learner Autonomy in University Students. Studies in Higher Education, 35(3), 351-359. https://doi.org/10.1080/03075070903502703

Ministry of Higher Education. (2012). The Undergraduate Study and Examinations Regulations. Riyadh, Saudi Arabia: King Fahd University of Petroleum \& Minerals. 
Nunan, D. (1996). Towards autonomous learning: some theoretical, empirical and practical issues. In R. Pemberton, E. S. L. Li, W. W. F. Or, \& H. D. Pierson (Eds.), Taking Control: Autonomy in Language Learning (p. 352). Hong Kong Hong Kong University Press.

Pennycook, A. (1997). Cultural Alternatives and Autonomy. In P. Benson, \& P. Voller. (Eds.), Autonomy and Independence in Language Learning. New York, NY: Routledge.

Risemberg, R., \& Zimmerman, B. J. (1992). Self - Regulated Learning in Gifted Students. Roeper Review, 15(2), 98-101. https://doi.org/10.1080/02783199209553476

Scharle, A., \& Szabo, A. (2000). Learner Autonomy: A Guide to Developing Learner Responsibility (Cambridge Handbooks for Language Teachers. Cambridge, UK: Cambridge University Press.

Sella, L. (2014). A Study on Autonomy and Its Influencing Factors in Adult Language Learners. Unpublished Master's thesis, Università Ca' Foscari Venezia Italy.

Shoaib, A., \& Dörnyei, Z. (2005). Affect in Lifelong Learning: Exploring L2 Motivation as a Dynamic Process. In P. Benson, \& D. Nunan (Eds). Learners' Stories: Difference and Diversity in Language Learning Cambridge, UK: Cambridge University Press.

Tamer, O. (2013). Students' Readiness for Autonomous Learning of English as a Foreign Language. Master's thesis, University of Sunderland.

Ushioda, E. (1996). Learner Autonomy 5: The Role of Motivation. Dublin, Ireland: Authentik Language Learning Resources, Ltd.

Wenden, A. L. (1998). Metacognitive Knowledge and Language Learning. Applied Linguistics, 19(4), 515-537. https://doi.org/10.1093/applin/19.4.515

Yang, N. D. (1999). The Relationship between EFL Learners' Beliefs and Learning Strategy Use. System, 27(4), 515-535. https://doi.org/10.1016/S0346-251X(99)00048-2

Zhang, L., \& Li, X. X. (2004). A Comparative Study on Learner Autonomy between Chinese Students and West European Students. Foreign Language World, 4, 15-23.

\section{Appendix A}

Descriptive statistics (means and standard deviations) of the questionnaire items in descending order of the mean.

\begin{tabular}{lll}
\hline Statement & $M$ & $S D$ \\
\hline 2. I attend my English language classes regularly. & 3.37 & 0.75 \\
\hline $\begin{array}{l}\text { 16. When I become involved in difficult tasks in English language classes, I try to stick } \\
\text { with them. }\end{array}$ & 3.22 & 0.80 \\
\hline
\end{tabular}

22. Whether students should design the teaching plan together with teachers or not, my opinion is:
A. Strongly agree
B. Agree
C. Neutral
D. Disagree
E. Strongly disagree

$3.21 \quad 0.80$

24. When I meet a word I do not know, I mainly:
A. Let it go
B. Ask the teacher about its meaning
C. Guess the meaning
D. Ask my classmates about its meaning

3.06 
E. Look it up in the dictionary

\begin{tabular}{|c|c|c|}
\hline 8. I think I have the ability to learn English well. & 3.01 & 0.90 \\
\hline 10. I note my strengths and weaknesses in learning English and improve them. & 2.94 & 0.47 \\
\hline
\end{tabular}

26. When I am asked to use technologies that I have not used before (e.g., internet discussion),
A. I typically try to learn new skills
B. I learn them following others
C. I feel worried using them.
D. I put it off or try to avoid it
E. I resist using them

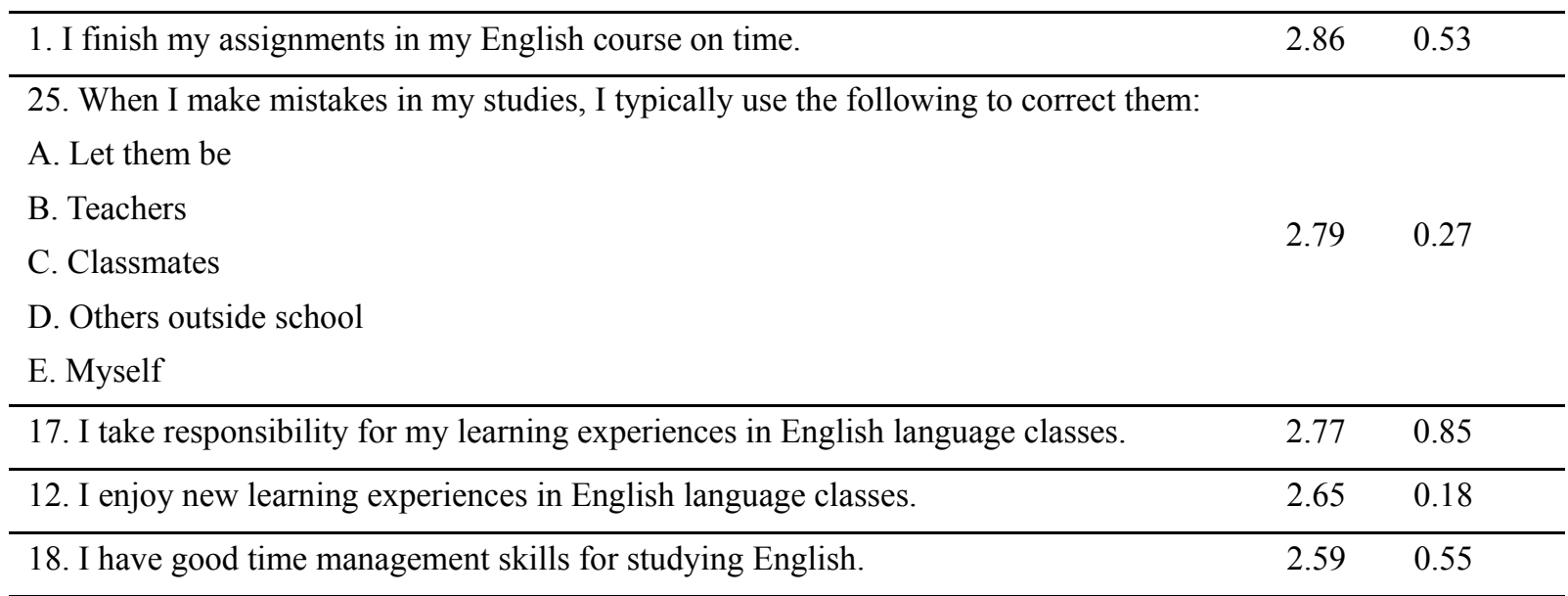

21. I think my success or failure in English study is mainly due to:

A. Luck or fate

B. The English studying environment

C. Studying facilities (aids)

D. Teachers

E. Myself

\begin{tabular}{lcc}
\hline 9. I reward myself, such as going shopping, playing, etc., when I make progress. & 2.46 & 0.50 \\
\hline 14. I enjoy being set at a challenge in English language classes. & 2.25 & 0.27 \\
\hline 15. I enjoy finding information about new topics in English on my own. & 2.24 & 0.39 \\
\hline
\end{tabular}

19. I study English here because:

A. It is a requirement to graduate from this school

B. Curiosity

C. Obtaining a good job

D. To complete higher studies

E. Of my interest in Anglophone culture

\begin{tabular}{|c|c|c|}
\hline 11. I choose books and exercises that suit me, neither too difficult nor too easy. & 2.23 & 0.34 \\
\hline $\begin{array}{l}\text { 6. I keep a record of my studies (e.g., making notes and summaries, keeping a diary, } \\
\text { writing reviews, etc.) }\end{array}$ & 2.14 & 0.44 \\
\hline 13. I am open to new ways of doing familiar things in English language classes. & 2.03 & 0.28 \\
\hline 4. I practice English outside the classroom. & 1.98 & 0.27 \\
\hline
\end{tabular}


3. In the class, I try to use every opportunity to take part in the activities where and when I can speak in English.

7. I make a practice test in the English language for myself before the actual exam.

1.88

0.44

20. I think the learner-teacher relationship is that of:
A. Receiver and giver
B. Raw material and maker
C. Customer and shopkeeper
D. Partners
E. Explorer and director

$1.73 \quad 0.78$

23. When the teacher asks questions for us to answer, I mostly like to:
A. Wait for other students to answer
B. Think and try to answer
C. Look up the answer in books and dictionaries
D. Clarify questions with the teacher
E. Join a pair/group discussion to answer

27. I think the following way is most useful in my English study:
A. Taking notes
B. Mechanical memory
C. Doing exercises in grammar, translation, words, etc.
D. Classifying or grouping or comparing
E. Group discussion

\begin{tabular}{llc}
\hline 5. I review before the class. & 1.29 & 0.85 \\
\hline 28. I typically use materials selected: & & \\
A. Only by teachers & & \\
B. Mostly by teachers & 1.05 & 0.76 \\
C. By teachers and by myself & & \\
D. Mostly by myself & & \\
E. Only by myself. & & \\
\hline
\end{tabular}

\section{Copyrights}

Copyright for this article is retained by the author(s), with first publication rights granted to the journal.

This is an open-access article distributed under the terms and conditions of the Creative Commons Attribution license (http://creativecommons.org/licenses/by/4.0/). 